\title{
Assessment Method on United Nation Sustainable Development Goals, Applied for a Sustainable City, with a Focus on Greater Khartoum Services
}

\author{
Hind Abdel Moneim Khogali ${ }^{1}$ \\ ${ }^{1}$ College of Architecture Engineering and Digital Design, Dar Al Uloom University, Riyadh city, Sadi Arabia \\ Correspondence: Hind Abdel Moneim Khogali, Consultant/Doctor Environmental Architectural Engineer, College \\ of Architecture Engineering and Digital Design, Dar Al Uloom University, Riyadh city, Sadi Arabia. E-mail: \\ ahind@dau.edu.sa
}

Received: October 20, 2021

doi:10.5539/jsd.v15n1p14
Accepted: November 27, $2021 \quad$ Online Published: December 27, 2021

URL: https://doi.org/10.5539/jsd.v15n1p14

\begin{abstract}
The first approach for environmentally sustainable development to the global community was introduced in 1992 in the United Nations conference on environment and development, the "Earth Summit", which took place in Rio de Janeiro, Brazil.(genda21). Defining Sustainable development as the one that meets the needs of the present generation without compromising the ability of future generations to meet their own needs.

Therefore, the study will focus on the United Nations Sustainable Development Goals UN-SDGs and the making of Sustainable cities. The aim of the research is to propose a framework to transform Greater Khartoum into a Sustainable city and to find out criteria for an Assessment Method that is applicable for Greater Khartoum. Which including providing Safe affordable housing and basic services, Sustainable transportation, Sustainable home settlements in the three towns, protect culture and Natural Heritage, Reduce Waste including water, air and solid waste, public access, Green-space, Support positive economic, social, and environmental links between urban and rural areas, National and local disaster risk reduction strategies, Interlinkages and implications for policy-making In addition, the methodology of the research focuses on defining, identifying, and measuring the indicators and sub-items. The measurement applied through survey and questionnaire. Distributed and distribute to all engineers specialized in architecture, urban, civil, electrical, and mechanical engineers in the three cities (KhartoumKhartoum North-Omdurman).

Finally, the outcomes of the research, applying the criteria of SDGs to evaluate the present situation in sustainable development criteria in Greater Khartoum; most of the indicator record results the research recorded results show that the goals were not achieved in most of the situations, between (20-30) especially in services (Table 1), waste management and open spaces are average (40-49). Will provide valuable recommendations towards improving the future and urban planning and sustainable development for the Capital city.
\end{abstract}

Keywords: Sustainable Development Goals, Greater Khartoum Sustainable City, measuring performance indicators (KPI) for Greater Khartoum

\section{Introduction}

Greater Khartoum as a city consists of three towns (Khartoum, Omdurman and Khartoum North); it is suffering from many environmental problems like waste disposal, increase of $\mathrm{CO} 2$ emission from cars and industrial areas, water waste. The increase in migration towards Khartoum city in the last $20^{\text {th }}$ years; these caused problems in services such as education, affordable houses for those people, hospitals, the basic life needs in goods, homes. Hamid (2010) and HABITAT, (2009).

This research is aiming to find sustainable city indicators according to SDGs11 sustainable development goals No.11 for UN. To be applied in Greater Khartoum. The project consists of two phases; phase one is finding out the indicators for the assessment of the sustainable city in a general framework. Phase 2 is applying the indicators on Khartoum city to find key performance indicator (KPI) measurement and percentage for each criterion.

\section{Literature Review}

United Nations set up sustainable Development Goals in UN, (1992) in the United Nations conference on 
environment and development, the "Earth Summit", which took place in Rio de Janeiro, Brazil (genda21), Fox (2000).

UN SDGs (UN, 2018) published criteria indicators (1) Safe affordable housing and (2) basic services, (3) Sustainable transportation, (4) Sustainable home settlements in the three towns, (5) Protect culture and Natural Heritage. (6) Reduce Waste including water, air, and solid waste, Reduce water waste, air, and solid waste, (7) Public access, Green-space. (8) Support positive economic, social, and environmental links between urban, and rural areas, (9) National and local disaster reduction strategies, (10) Support least developed countries, including through financial and technical assistance, in building sustainable and resilient buildings utilizing local materials, (11) Interlinkages and implications for policy-making. Anderson, (2011) Studied measuring cities indicators for Sweden city focuses on the focus in vision, Indicator framework, indicator selection, stockholders' participation, communication strategy visual design, the study ended by cases study. Commission, (2018) Discussed China Sustainable Index which consists of some indicators like basic needs, Recourses Efficiency, Environment Clean Lines, Built Environment, and Commandment to the environment. The Commission, (2018) Discussed the European tools for sustainable cities such as, change climate mitigation, sustainable urban mobility, sustainable land use, nature and biodiversity, air quality, noise, waste, water, energy, green growth and eco-innovation, energy performance, and governance. KAUST, (2013) presented proposal green building for certificate system for the KSA The development site, transport, atmosphere, indoor air quality, using environmental quality, water, energy, material, eco-innovation, culture, and labour. Ministry, (2018) discussed the parameters of Saudi Arabia smart city the indicators are smart buildings, mobility, security for citizens, healthcare, energy, digitization. Abdelmoneim, H., (2017) a presented paper about categories for the sustainable neighbourhood the indicators are sustainable site, neighbourhood design, pattern and construction, material and resources, water, Energy, environmental design process and emission and safety. Abdelmoneim, H., (2005) discussed the renewable energy resources in Greater Khartoum which including solar energy and wind energy.

UN-HABITAT, (2015) Published a report about Saudi Future Cities and announced the program (FSCP) the focus indicators are the program studied several cities in Saudi Arabia including Makkah city. UN-HABITAT, (2016) Published a report about Saudi Future Cities and announced the program (FSCP) in Al Medina, UN-HABITAT, (2017) Published a report about Saudi Future Cities and announced the program (FSCP) in Judah city.

HABITAT, (2018) Published a report about Saudi Future Cities and announced the program (FSCP) in Al Riyadh city, the main indicators are urban government and legislation, productivity, infrastructure productivity, quality of life, equity and social. Environmental and sustainability. UN, (2018) and Forum, H. L. P., (2018) discussed and published UNSDGs.

\section{The Methodology}

The research is based on UN SDGs for sustainable cities. Therefore, the methodology first starts by define, identify then measure the indicator which are safe affordable housing and basic services, sustainable transportation, sustainable home settlements in the three towns, protect the culture and Natural Heritage. Reduce waste including water, air and solid waste, public access, green space, support positive economic, social and environmental links between urban and rural areas. National and local disaster risk, reduction strategies, Interlinkages and implications for policy-making. Consequently, after a comprehensive literature review in urban indicators applying in Europe, Asia and on the region, the researcher applies the survey and questionnaire through Google survey in the social media, focus on engineering groups. The results were analyzed in tables and figures. Finally, the results were discussed for the conclusion. 


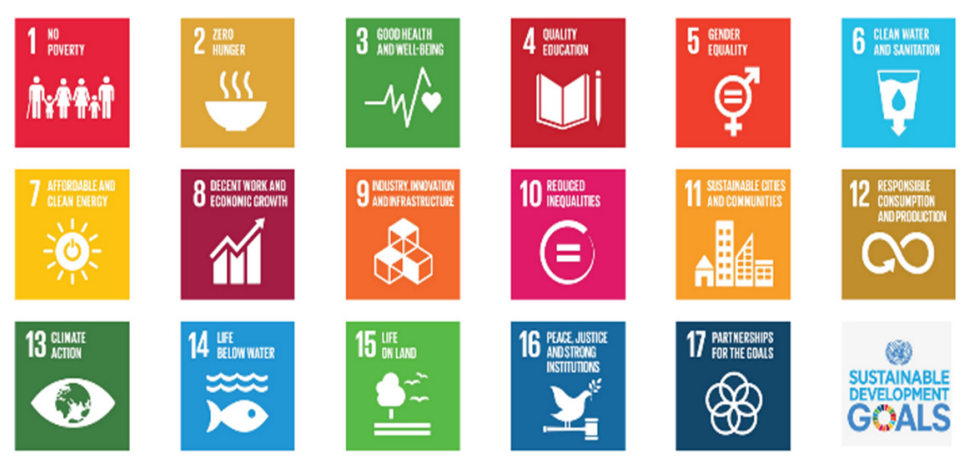

Figure 1. UNSDGs, The research focuses on goals No.11, sustainable cities

\subsection{Define the Indicator}

Commission, (2018) define the indicator as "Indicator: a parameter, or a value derived from parameters, which points to, provides information about, and/or describes the state of a phenomenon/environment/area, with a significance extending beyond that directly associated with a parameter value".

\subsection{How to Identify the Indicators}

1) The indicator should be remarkable

2) In addition, it could be measured as a percentage

3) Consequently, The measures could be updated

4) Furthermore, It required good data based on monitoring

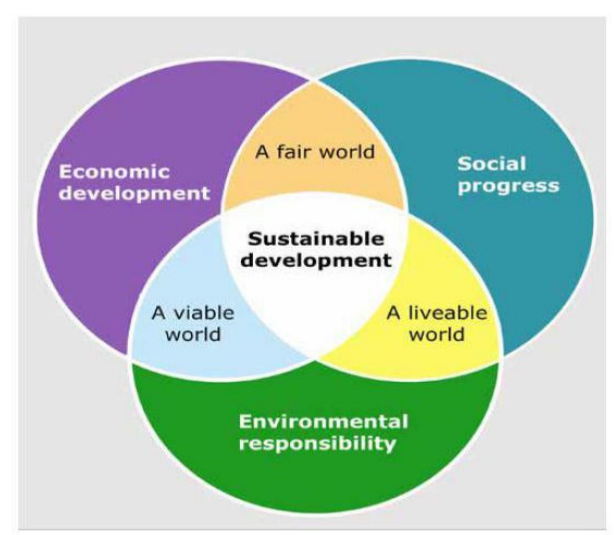

Figure 2. Shows the three main components of sustainable development, source: Commission, (2018)

\subsection{How to Measurement the Indicators}

The indicator could be measured by survey and Questionnaire. The researcher applies the survey and questionnaire through a Google survey in the social media, focus on engineering groups. The results were analyzed in tables and figures 
Table 1. The evaluation scale

\begin{tabular}{lll}
\hline The evaluation & $\begin{array}{l}\text { The evaluation } \\
\text { scale }\end{array}$ & The meaning of the evaluation \\
\hline \multirow{2}{*}{$\begin{array}{l}\text { Very strong } \\
\text { factor }\end{array}$} & $\begin{array}{l}\text { Achieve the goals } \\
\text { There is policy, plan, apply, measured, with benchmarking and recycling } \\
\text { the process after } 5 \text { years }\end{array}$ \\
\hline Strong Factor & $(60-69)$ & $\begin{array}{l}\text { Achieve the goals } \\
\text { There is policy, plan, apply, measured, with benchmarking }\end{array}$ \\
\hline \multirow{2}{*}{$\begin{array}{l}\text { Moderate } \\
\text { Weak }\end{array}$} & $\begin{array}{l}\text { Achieved the goals } \\
\text { There is policy, plan, apply, measured }\end{array}$ \\
\hline Very Weak & $(40-49)$ & Not achieve the goals \\
\hline
\end{tabular}

\subsection{The Survey and Questionnaire}

The survey distributed by Google forms through many engineering groups in social media, Architects, urban Eng., surveys Eng., mechanical Engineer, civil and Electrical Engineer. The number of responses is 100.

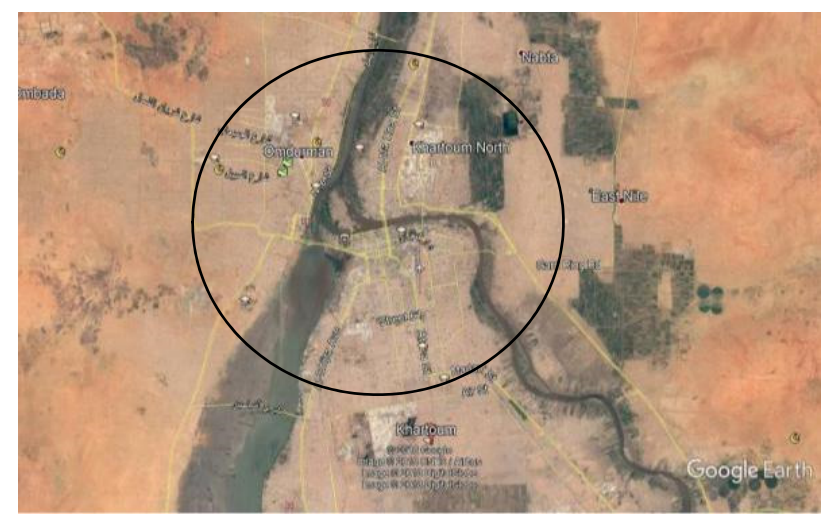

Figure 3. Google Seattleite image, Greater Khartoum including the three towns (Khartoum, Khartoum North, and Omdurman. The circle shows the limit of the study. Khogali, H., (2019)

\section{The Results}

The results are shown in the following figures from Fig.4 to Fig.17. In addition, Table 1 shows the average result for each indicator and table 2 showed the checklist results evaluation for each indicator the average result is recorded as safe affordable houses $(20 \%)$, clean energy $(16 \%)$, clean water $(19 \%)$, good health $(22.6 \%)$, good education $(17 \%)$, and transportation $(15 \%)$, reduce waste $(40 \%)$, sustainable home settlement $(15 \%)$, public access to green space (30\%), disaster reduction and strategies (29\%), support least development strategies (29\%), support positive economics (30\%) and interlink to policy making $(21 \%)$, all the results were below the average and not achieved the goals.

The results are shown in the following 


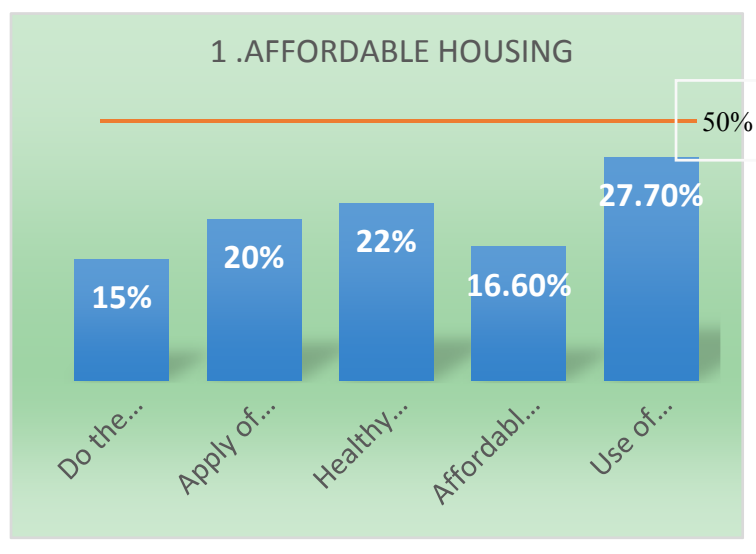

Figure 4. Shows the Affordable housing results

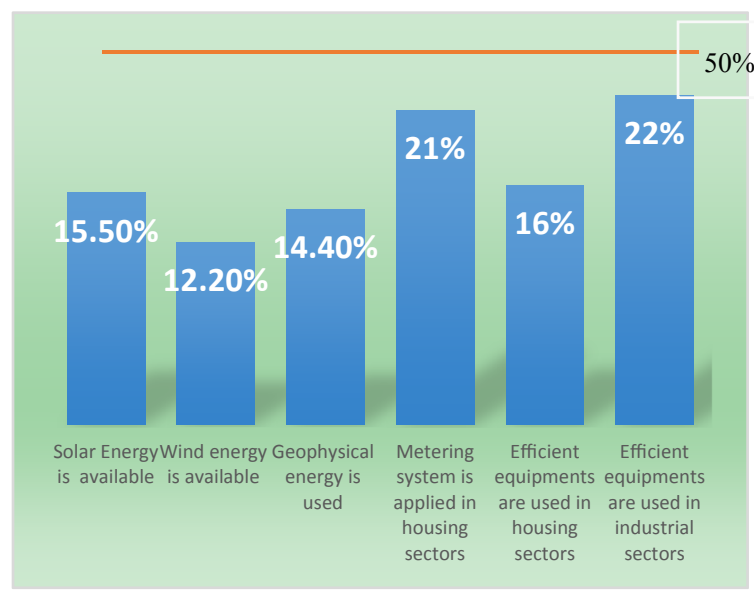

Figure 6. Shows the results of clean energy

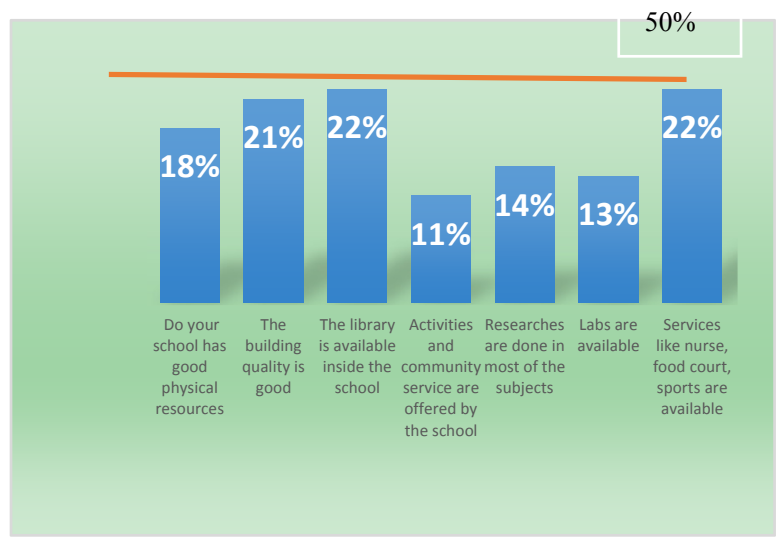

Figure 7. Shows education efficiency results

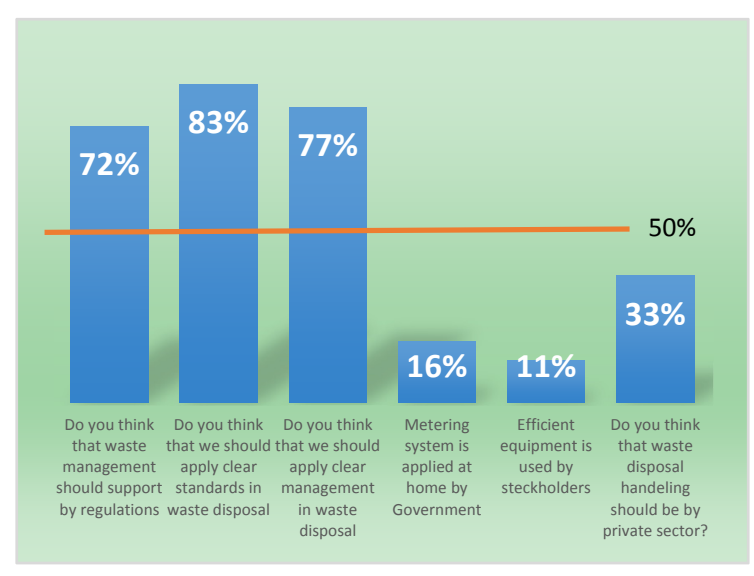

Figure 5. Shows the Services: Water efficiency results

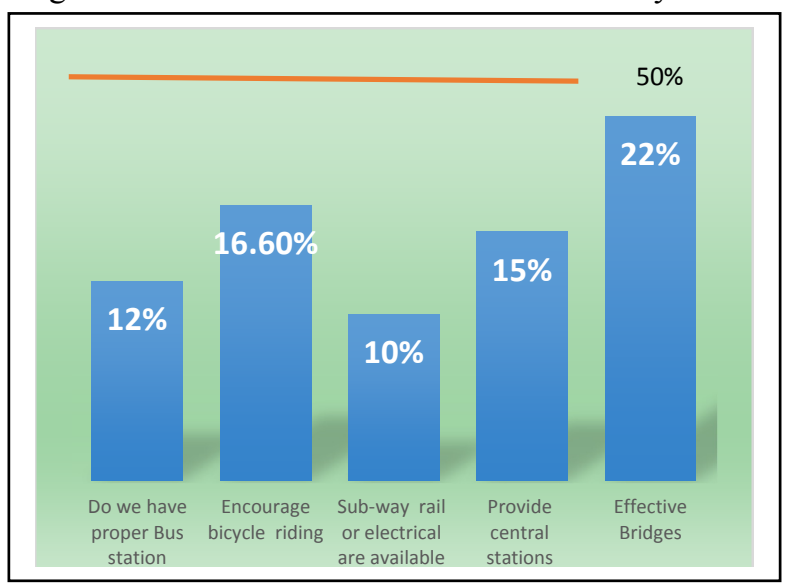

Figure 9. Sustainable Transportation results

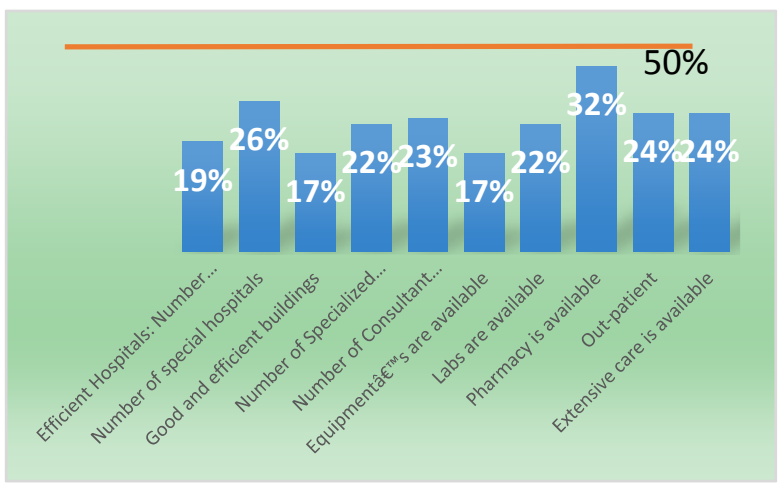

Figure 8. Shows Hospitals efficiency results 


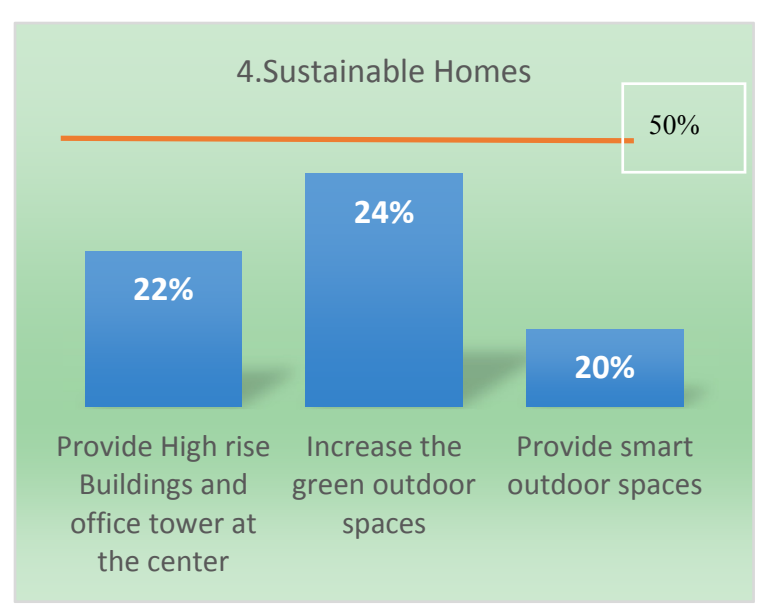

Figure 10. Shows Sustainable homes results

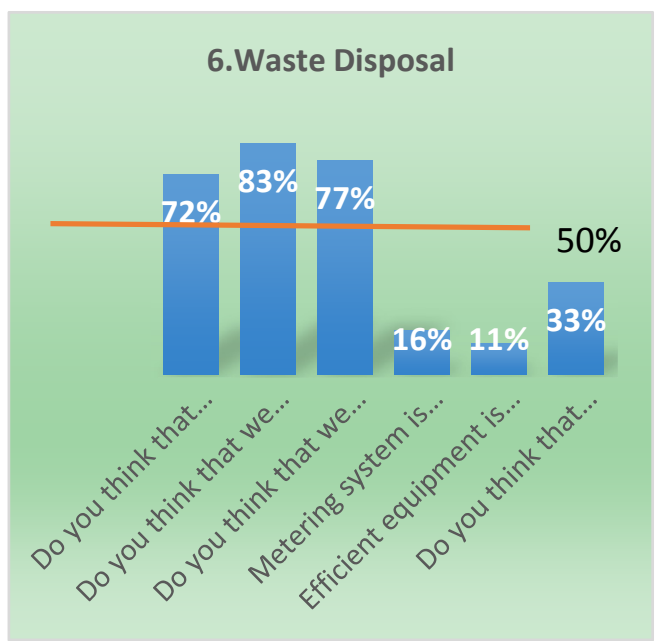

Figure 12. Shows waste disposal results

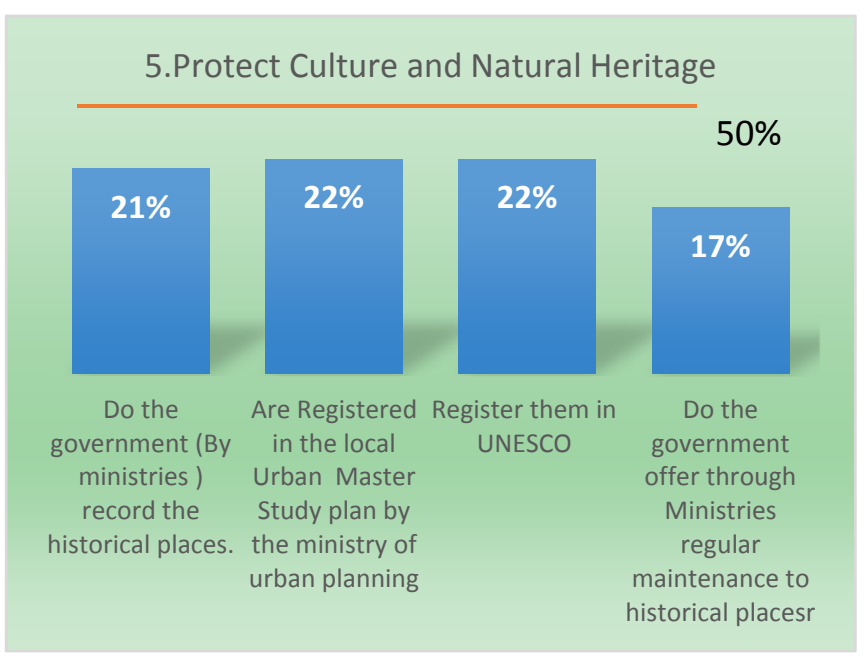

Figure 11. Shows protect the culture and natural heritage results

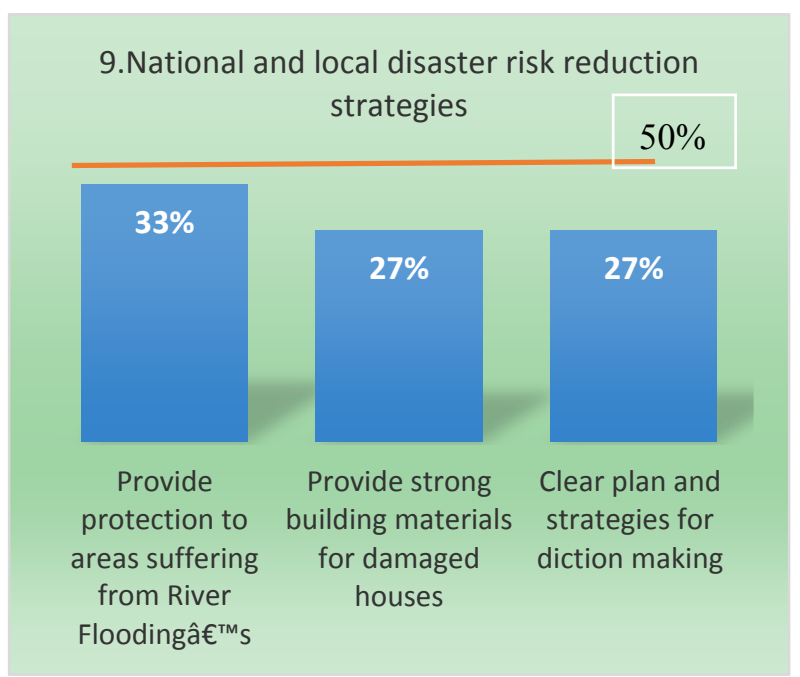

Figure 15. Shows national and local disaster risk Reduction strategies 


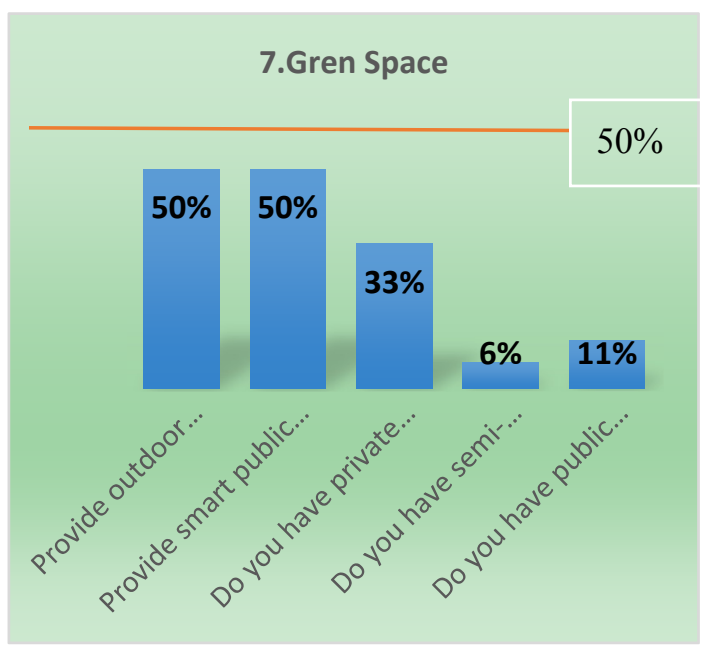

Figure 13. Shows Green space results

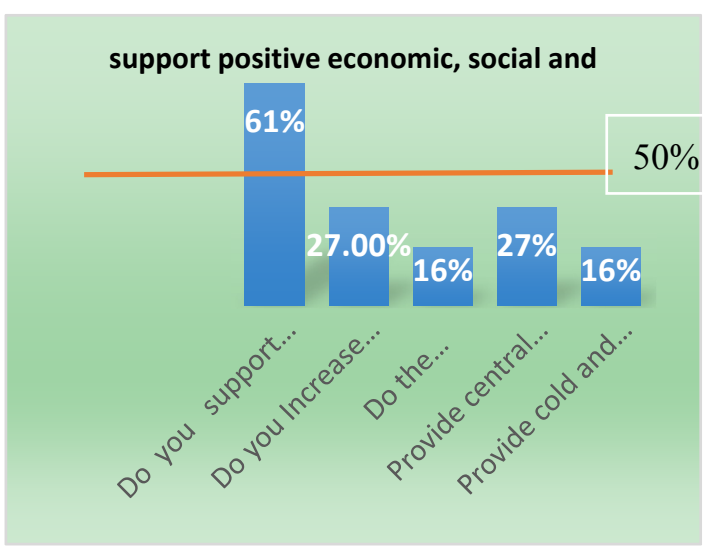

Figure 14. Shows support positive economic, social and environmental links between urban and rural areas

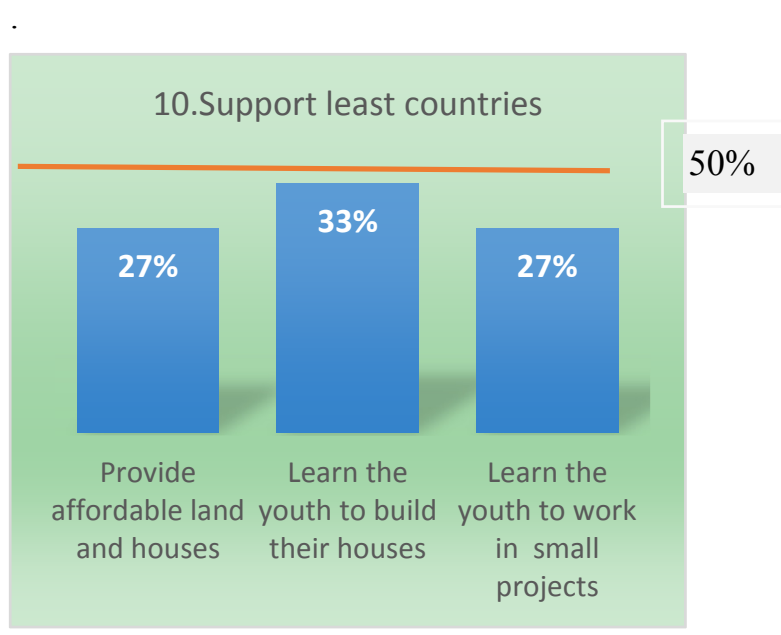

Figure 16. Shows the results of supporting the least countries

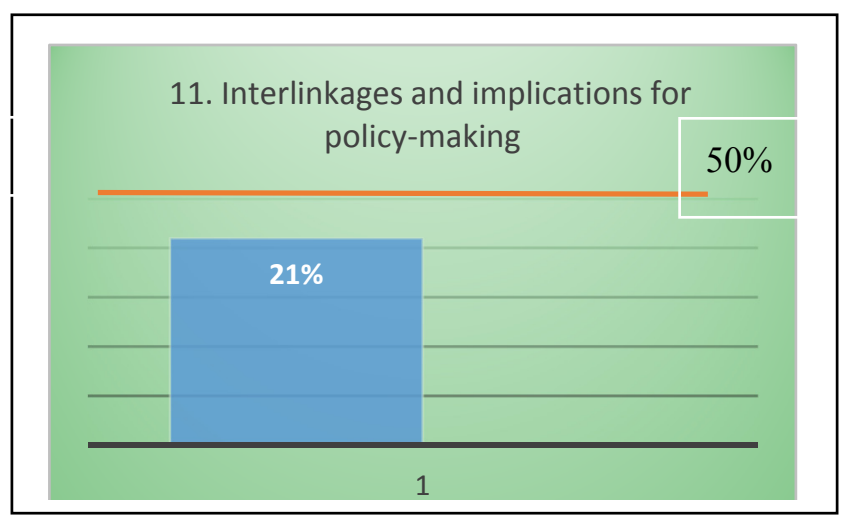

Figure 17. Shows the results of interlinks and implications for policymaking

\section{Discussion}

The Discussion shows in depth all the points here related to SDG's, the study focuses on Goal no 11' Make cities inclusive, safe, resilient and sustainable.

\subsection{Safe Affordable Housing and Basic Services}

Greater Khartoum affordable houses are (80\%) and 20\% lived in illegal houses.

The average result of the survey is shown in table $1,20 \%$ which is evaluated according to the scale as weak.

The results of the survey were shown in Fig. 4 as follows

Do the government apply for global building standards (15\%) and apply of local sustainable building standards $(20 \%)$, the stockholder's $(22 \%)$ builds healthy houses, and the government $(16.6 \%)$ and use of local building materials (27.7\%) provide affordable houses.

The Challenges is providing sustainable affordable houses, the use of local building materials and the researcher.

Note that all the result for this indicator is below the average (20\%) and the indicator has not achieved the goals. The priority for improvement is applying of global and local sustainable buildings standards.

\subsection{The Services}

\subsubsection{The Drainage System Infrastructure}

The drainage net in Khartoum 2 since The Colonial period. Other places used well and septic tank by $70 \%$, Gravel 
and Sand for illegal areas by 20\%, which contaminate the underground water (Yassin, 2013).

The average result for clean water is shown in table 1 , which is 19.3 , which is evaluated according to the scale as very weak.

The result of the survey in water efficiency shown in Fig. 5 as follows: Efficient potable water for drinking is used and available (25\%), a water-metering system is applied (21\%), do you use grey water recycling $(12 \%)$.

The challenges are increasing quality according to the World Health Organization (WHO) standards. Enhance monitoring for the current situation. Identifying its impact on Human Health and encourage people to follow orientations.

The average result for the clean water indicator is $(19.2 \%)$, the result of the indicator is below the average, and the indicator has not achieved the goals. The priority for improvement is applying the WHO standards for potable water.

\subsubsection{Clean Energy}

The results were shown in figure 9 solar energy is available (15.5\%), wind energy is available (12.2\%), geophysical energy is used (14.4\%), metering system is applied in the housing sector (21\%), and efficient equipment is used in the housing sectors (16\%) efficiency is used in the industrial sector in operation $(22 \%)$.

The challenges are applying renewable energy like solar energy and wind energy and others in Greater Khartoum.

The solutions for the future could be applying more projects using solar energy and wind energy; the government could help in establishing solar plant by sharing with investors in this field.

The average result for clean energy is $(16.8 \%)$, the result of the indicator is below the average, and the indicator is not achieved the goals. The priority for improvement is applying energy efficiency plans and policies including solar energy system for housing and industrial sectors by the government and the stockholders.

\subsubsection{Efficient Education}

The results for education efficiency shown in fig. 7 is as follows:

The results of quality education were shown in figure 6: Do your school has good physical resources (18\%), and the building quality is good $(21 \%)$, the library is available inside the school $(22 \%)$, activities and community service are offered by the school (11\%). The researchers are done in most of the subjects (14\%), are the labs are available (13\%) and the services as a nurse, food-court, and sports are available $(22 \%)$.

The result for the indicator is below the average (17\%) and the indicator has not achieved the goals. The priority for improvement is applying a better education, improvement the buildings quality, providing libraries with good numbers of books, eBooks, digital libraries, encourage the students for reading and writing researches, good activities such as sports and community participation.

\subsubsection{Efficient Hospitals}

\section{The result of efficient hospitals shown in fig 8 as follows:}

Do the government offer efficient hospitals (19\%), number of special hospitals (26\%), good and efficient buildings (17\%), number of specialized doctors (22\%), number of consultant doctors (23\%), equipment are available (17\%), labs are available (22\%), pharmacy is available (32\%), outpatient (24\%) and extensive care (24\%).

The challenges are establishing green and sustainable hospitals, providing efficient equipment and supportive treatment for all people.

The result for efficient hospitals is below the average (22.6\%) and the indicator did not achieve the goals. Good solutions for the future are built up efficient hospitals by supporting and help of investors.

\subsection{Sustainable Transportation}

In the three towns (Khartoum, Omdurman, and Khartoum North), there are main transportation bus-stations was built out of the centre to reduce the disadvantages of heavy traffic. There are new bridges like Tuti Island and Almak Nimer new bridges constructed on 2008 and 2009 consequently. (UN-HABITAT, 2016).

The result according to the survey shown in fig 9 as follows:

Do we have proper bus station (12\%), and encourage bicycle riding (16.6\%), the subway is available (10\%), provide central station (15\%) and effective bridges $(22 \%)$.

The challenges are constructing of new roads especially ring road, subway around the three towns and more new bridges. 
The result for the indicator is $15 \%$, the result of the indicator is below the average, and the indicator has not achieved the goals. The priority for improvement is applying efficient bus station, subway, central bus station, efficient bridges, and ring roads.

\subsection{The Sustainable Homes Settlements in the Three Towns}

Reduce the physical expansion over the agriculture lands; urban sprawl is increasing in Greater Khartoum.

The results from the survey are shown in fig 10 as follows:

Provide high-rise buildings and office tower at the centre (22\%), increase the green outdoor spaces (24\%), provide smart outdoor space (20\%).

Challenges are increasing the high-rise buildings, improve the outdoor environment in a landscape, apply to smart outdoor gardens and parks, and improve the transportation system. Establishing of new sustainable urban community and housing. Using proxy indicators.

The result for the indicator is $22 \%$, the result is below the average and the indicator has not achieved the goals. The priority for improvement is applying high-rise buildings and providing green space at the centre of Greater Khartoum.

\subsection{Protect Culture and Natural Heritage}

The local building regulations for the National Capital of the Republic of Sudan, and the environmental framework Planning, (2014) by The Ministry of Housing in Khartoum stated the primary setting taking into account historical places and buildings preservation like Khartoum University buildings, Abdel Ghaume Gate, Al Mahdi old Palace, some of Churches In Khartoum.

The results from the survey are shown in fig 11 as follows:

Do the government record the historical places (by the ministries) (21\%), are registered in the local urban master plan (22\%), register them in UNESCO (22\%) and offers regular maintenance (17\%).

Challenges are Identify the historical places and register them in UNESCO Global Historical places. Many historical places in Greater Khartoum were found since the colonial period and Othman Architecture.

The result for the indicator is $20.5 \%$, the result is below the average and the indicator has not achieved the goals. The priority for improvement is registering the historical places in UNESCO offers regular maintenance and reuse.

\subsection{Reduce Waste}

The waste is including water, air and solid waste: Greater Khartoum is suffering from solid waste, gaseous and water waste.

The average result is $48 \%$, which is evaluated according to the scale as average

The results from the survey are shown in fig 12 as follows:

Do you think that waste management should support by regulations (72\%), Do you think that we should apply clear standards in waste disposal (83\%), Do you think that we should apply clear management $(77 \%)$, meeting system is applied (16\%), efficient equipment is used by stockholder's $(11 \%)$, and do you think that waste disposal handling should be by private sector (33\%).

Challenges: Government and NGOs should set up regulations and management solutions for private and industrial sectors to minimize the solid, gaseous and water waste. Increase quality according to WHO standards. Enhance monitoring for the current situation. Identify its impact on Human Health and encourage people to follow orientations.

The result for the indicator is $40 \%$, the result is within the average, and the result has achieved the indicator. Priority for improvement is setting up regulations for waste management and monitoring.

\subsection{Public Access}

Public space is improved, and the government removes Khartoum Hospital to the suburb area. As well as the International Khartoum airport will be removed to the suburb area in Omdurman and reuse its place of public green space.

The result from the survey is shown in fig 13 as follows:

Provide outdoor green space (50\%), provide smart public space (50\%), do you have a private garden in your home $(33 \%)$, do you have a semi-public green area at the centre of your neighbourhood $(6 \%)$ and at the centre of your 
city $(11 \%)$.

The average result is $(30 \%)$ the result is weak.

Challenges: Transportation efficiency, as well as the, improve road structure, and its drainage net, provide more of public space improvement, more land allocated and reuse these areas for recreations. Provide safety urban space especially for children and women.

The result for indicator public space is $30 \%$, the result is below the average, and the indicator did not achieve the goals. The priority for improvement is applying the public space in all urban levels especially at the middle of the neighborhood and at the centre of the three towns.

\subsection{Support Positive Economic, Social, and Environmental Links between Urban and Rural Areas}

To provide a global overview of the state of urban policy at the national level and serves the purpose of monitoring this indicator through four categories: Feasibility, Diagnosis, Formulation, and Monitoring and Evaluation (SDGs). Greater Khartoum has a strong relationship with the suburb areas, especially in the agriculture industry, Cattles and animals' industry. The Government between Greater Khartoum and the rural areas established fast roads.

The results from the survey are shown in fig 14 as follows:

The questions of the survey and the results: Do you support positive economic, social, and environmental links between urban and rural areas (61\%), do you increase the industry in the rural areas $(27 \%)$, do the government provide fast and efficient roads $(16 \%)$, provide central markets $(27 \%)$, provide cold and dry store $(16 \%)$. The average result is $(29.5 \%)$, the result is weak.

Challenges are providing fast and proper transportation system between the Greater Khartoum and the rural areas, provide central market to welcome these products with cold and dry warehouses, control the prices of these products, regular maintenance of these roads, and support the industry in the rural areas.

The result for the indicator is $30 \%$, the result is below the average and the indicator did not achieve the goals. The priority for improvement is supporting the industries in rural areas, providing fast roads and central markets with all the facilities could help in a successful process.

\subsection{National and Local Disaster Reduction Strategies}

Supporting sustainable and resilient cities and human settlements and the achievement of the SDGs requires that disaster risk reduction integrated into core social, economic and development planning (SDGs). Greater Khartoum suffering from flooding, Abdulla (2008) stated in his M.Sc. research that Sudan suffered the most destructive floods during the last 20 years. Many cities, especially Khartoum (the capital of Sudan). In addition, the minor earthquake happened in 1946, 1988, 1993, 2010 and 2013 between 3 to 5 Richter. Without any serious effect.

The results from the survey are shown in fig 15 as follows:

Provide protection to the area suffering from river Nile (33\%); provide strong building materials for damaged houses (27\%), a clear plan and strategies for diction making (27\%).

Challenges are applying the polices to protect the areas suffering from flooding the River Nile

The result for the indicator is $29 \%$, the result is below the average and the indicator has not achieved the goals. The priority for improvement is applying strategies for protecting the areas suffering from flooding the River Nile.

\subsection{Support the Least Development Countries}

Including through financial and technical assistance, in building sustainable and resilient buildings utilizing local materials. The construction industry has a significant impact on material extraction, consumption of natural resources and human comfort (SDGs). Greater Khartoum attracting people from South Sudan, Ethiopia, Eritrea, and from East and West Sudan. The migration reach 20\% of the total Khartoum Population Most of them lived in illegal houses. The Ministry of Urban Planning with UN-HABITAT program me to have a good on-going plan to own these lands and provide services for water and energy.

The result from the survey is shown in fig 16 as follows:

Provide affordable land and houses (27\%), learn the youth to build their houses (33\%) and learn the youth to work in small projects $(27 \%)$.

The average result is $29 \%$ and it is weak Challenges are providing safe, low-cost houses, provides services like energy and water, waste disposal to those people. Incur rage people for jobs; construct their houses by bricks and stones. 
The result for the indicator is $29 \%$; the result is below the average; the result did not achieve the goals. The priority for improvements is providing affordable land, learn the youth to build their houses and allocate the land for them.

\subsection{Interlinkages and Implications for Policy-Making}

Connect the SDGs to urban policies and a clear impact on cities and human settlements. Challenges: update and link the local building regulations for the National Capital of the Republic of Sudan, and the environmental framework (Planning, 2014) by The Ministry of Housing in Khartoum.

The result from the survey is shown in fig 17 is $(21 \%)$, the result of the indicator is below the average, and the indicator did not achieve the goals.

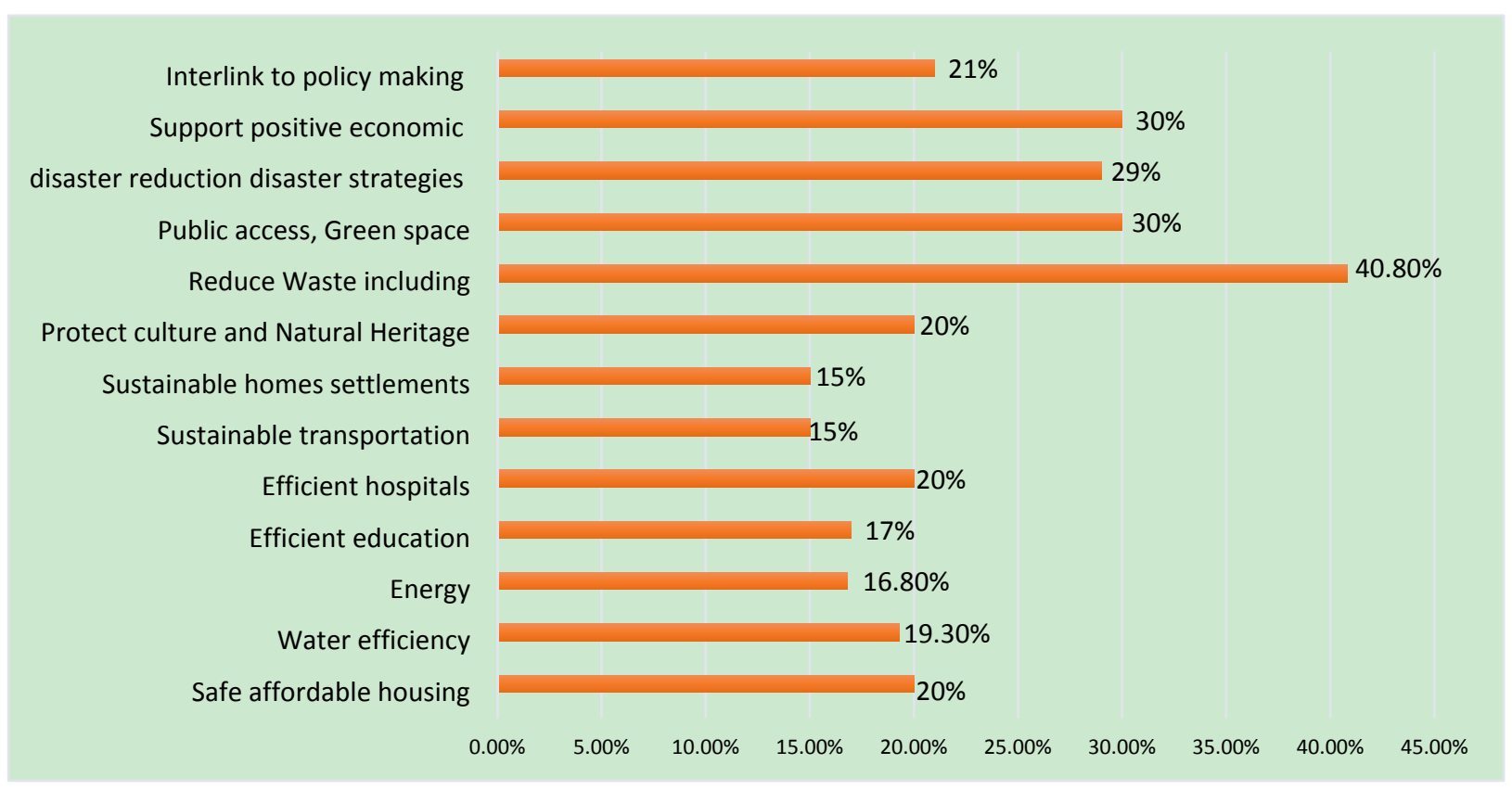

Figure 18. The evaluation for all indicators and the average result

Table 2. The Evaluation of the results for each indicator

\begin{tabular}{lllll}
\hline No of indicator & The indicator & The percentage & The evaluation & The result \\
\hline 1 & Safe affordable housing & $20 \%$ & Weak & Not achieved the goals \\
\hline 2 & Services & & & \\
\hline 2.1 & Water efficiency & $19.3 \%$ & Weak & Not achieved the goals \\
\hline 2.2 & Energy & $16.8 \%$ & Weak & Not achieved the goals \\
\hline 2.3 & Efficient education & $17 \%$ & Weak & Not achieved the goals \\
\hline 3 & Efficient hospitals & $20 \%$ & Weak & Not achieved the goals \\
\hline 4 & Sustainable transportation & $15 \%$ & Very Weak & Not achieved the goals \\
\hline 5 & Sustainable homes settlements & $15 \%$ & Very Weak & Not achieved the goals \\
\hline 6 & Protect culture and Natural Heritage & $20 \%$ & Very Weak & Not achieved the goals \\
\hline 7 & Reduce Waste including & $40.8 \%$ & Average & Not achieved the goals \\
\hline 8 & water, air and solid waste & & Weak & Not achieved the goals \\
\hline 9 & Public access, Green space & $30 \%$ & Weak & Not achieved the goals
\end{tabular}




\begin{tabular}{llcll}
\hline 10 & Support positive economic & $30 \%$ & Weak & Not achieved the goals \\
\hline 11 & Interlink to policy making & $21 \%$ & Weak & Not achieved the goals \\
\hline & Average result & $\mathbf{2 5 \%}$ & Not achieve the goals & Not achieved the goals \\
\hline
\end{tabular}

\section{The Research Outcome}

The research outcome is summarized in table 2 and figure 18

1) The research outcomes is finding general framework assessment Method to Evaluate Greater Khartoum in SDGs, No.11 in all categories under sustainable city. Which are: providing Safe affordable housing and basic services, Sustainable transportation, Sustainable home settlements in the three towns, protect culture and Natural Heritage, Reduce Waste including water, air and solid waste, public access, green space, Support positive economic, social and environmental links between urban and rural areas, National and local disaster risk reduction strategies, Interlink ages and implications for policy-making

2) Reporting the present situation, challenges, and future for each indicator.

3) Providing monitoring for the present achievements for each indicator in SDGs applied in Greater Khartoum.

4) Providing sustainable affordable houses and use of local building materials

5) Applying the WHO standards for potable water regular maintenance and improvement

6) Applying energy efficiency plans and policies including solar energy system for housing and industrial sectors by the government and the stockholders.

7) The priority for improvement is applying a better education, improvement the buildings quality, providing libraries with good numbers of books, eBooks, digital libraries, encourage the students for reading and writing research, good activities such as sports and community participation.

8) For hospitals good solutions for the future are building up efficient hospitals by supporting and help of investors.

9) The priority for improvement is applying efficient bus station, subway, central bus station, efficient bridges, and ring roads.

10) The priority for improvement is applying high-rise buildings and providing green space at the cenre of Greater Khartoum.

11) The research recommends protecting the historical and cultural places; by record them in Khartoum strategic plan, regular maintenance, and record them in UNESCO world heritage places.

12) Reducing solid, water and gaseous waste, set up regulations for people, and companies to manage the waste will be effective.

13) Public access, to the green space in different levels of the urban, indoor garden, intermediate green space at the middle of the neighbourhoods, and large green space and smart public space at the middle of the city.

14) Providing solutions for local disaster, reduce risk, and provides strategies, Set -up strategies in managing, the disaster especially in flooding season will be effective.

15) Supporting least developed countries, by providing suitable, healthy homes and services to them, allocate the land, encourage youths to build their homes, and learn them small projects

16) Linking the SDGs to local urban planning policies and to policymaking strategies.

\section{Acknowledgements}

This research acknowledges to Dar Al Uloom University, for their continuous help, and to Sudan Sustainable Building Council, especially regulation and rating system team.

\section{References}

Abdelmoneim, H. (2005). The Environmental Impact of Gaseous by Product and pollutants in Waste Water at Khartoum Refinery. Khartoum, Sudan, M.Sc. Institute of Environmental Study, University of Khartoum.

Abdelmoneim, H. (2017). Sustainable Eco Neighbourhood Assessment Method in Residential Neighbourhood for Greater Khartoum. International Conference for Future Sustainability (ICFS), Applied science University \& London South Bank University, Bahrain, Conference proceeding. 
Abdelmoneim, H. (2019). Sustainable -Eco Building -Assessment Method to Evaluate Residential Buildings in Greater Khartoum. $\mathrm{PhD}$ research, Khartoum University, Faculty of Architecture

Abdulla, M. (2008). M.Sc. research on Flood Analysis in the Blue Nile a case study of Flood Simulation in Khartoum with Climate Change Scenarios. Khartoum, Sudan: UNESCO, Institute of water education.

Anderson, L. (2011). Measuring Sustainable Cities. Sweden: Examensarbete Hållbar Utveckling.

Commission, E. (2018). Indicators for Sustainable Cities. Paris: Europe Union.

Forum, H. L. P. (2018). 2018 Review of SDGs implementation: SDG 11. USA: Sustainable development.UN.org.

Fox, W. (2000). Ethics and Built Environment (1st ed.). USA: Routledge.

Habitat, U. (2009). Urban Sector Studies and Capacity Building for Khartoum State. Nairobi, Kenia: United Nations Human Settlements Program.

Hamid, G. (2010). Incremental Housing in Khartoum, Paradigm Shift. Khartoum, Sudan, Faculty of Architecture, University of Khartoum.

KAUST. (2013). Evaluation of The Green Industry in Saudi Arabia and the GCC Region: Technologies, Market, Assessment and Business Opportunities. Riyadh, KSA: King Abdulla University for science and Technology.

Ministry. (2017). Road to Development, Advanced and Sustainable Economy in Saudi Arabia via Smart Cities. The Second Urban Forum. Judah, Saudi Arabia.

Planning, M. O. U. (2016). Sudan Report on Sustainable Development. UK: UN-HABITAT.

Planning, T. M. O. U. (2014). KSP Plan, Khartoum Structure Plan, Khartoum, Sudan: The Ministry of Urban Planning.

UN. (1992). United Nation Sustainable Development. Brazil: United Nations Conference on Environment \& Development.

UN. (2018). Sustainable Development. Retrieved November 20, 2018, from https://sustainabledevelopment.un.org/sdgs

UN-HABITAT. (2015). Future Saudi Cities. Saudi Arabia: UN-HABITAT and Ministry of Municipal and Rural Affairs, Makkah, Saudi Arabia.

UN-HABITAT. (2016). Future Saudi Cities. Saudi Arabia: UN-HABITAT and Ministry of Municipal and Rural Affairs, Medina, Saudi Arabia.

UN-HABITAT. (2018). Future Saudi Cities. Saudi Arabia: UN-HABITAT and Ministry of Municipal and Rural Affairs, in Riyadh, Saudi Arabia.

Yassin, N. (2013). Solar Energy Industry in Sudan. Sudan/Khartoum: Future University.

\section{Appendix}

The assessment method to evaluation the Sustainable City indicators according to SDGs

\begin{tabular}{|c|c|c|c|c|c|c|c|}
\hline \multirow{2}{*}{$\begin{array}{c}\text { No of } \\
\text { indicator }\end{array}$} & \multirow[t]{2}{*}{ Focus indicators } & \multicolumn{5}{|c|}{ The Evaluation range } & \multirow{2}{*}{$\begin{array}{l}\text { The } \\
\text { evaluation } \\
\text { Evaluation } \\
\text { from 5/5 }\end{array}$} \\
\hline & & $\begin{array}{l}\text { Strongly } \\
\text { disagree } \\
\underline{0 \%-24 \%}\end{array}$ & $\begin{array}{l}\text { Disagree } \\
\underline{25 \%-} \\
\underline{49 \%}\end{array}$ & $\begin{array}{l}\text { Average } \\
\underline{50 \%}\end{array}$ & $\begin{array}{l}\text { Agree } \\
\underline{51-75 \%}\end{array}$ & $\begin{array}{l}\text { Strongly } \\
\text { Agree } \\
\underline{76 \%-} \\
100 \%\end{array}$ & \\
\hline & & $\circ$ & $\underline{\mathrm{x}}$ & $*$ & $\bullet$ & $\checkmark$ & \\
\hline \multirow[t]{3}{*}{1} & Safe affordable housing & & & & & & \\
\hline & $\begin{array}{l}\text { Do the government Apply of Global } \\
\text { building standards? }\end{array}$ & o & & & & & $1 / 5$ \\
\hline & $\begin{array}{l}\text { Apply of Local Sustainable Building } \\
\text { Standards }\end{array}$ & o & & & & & $1 / 5$ \\
\hline
\end{tabular}




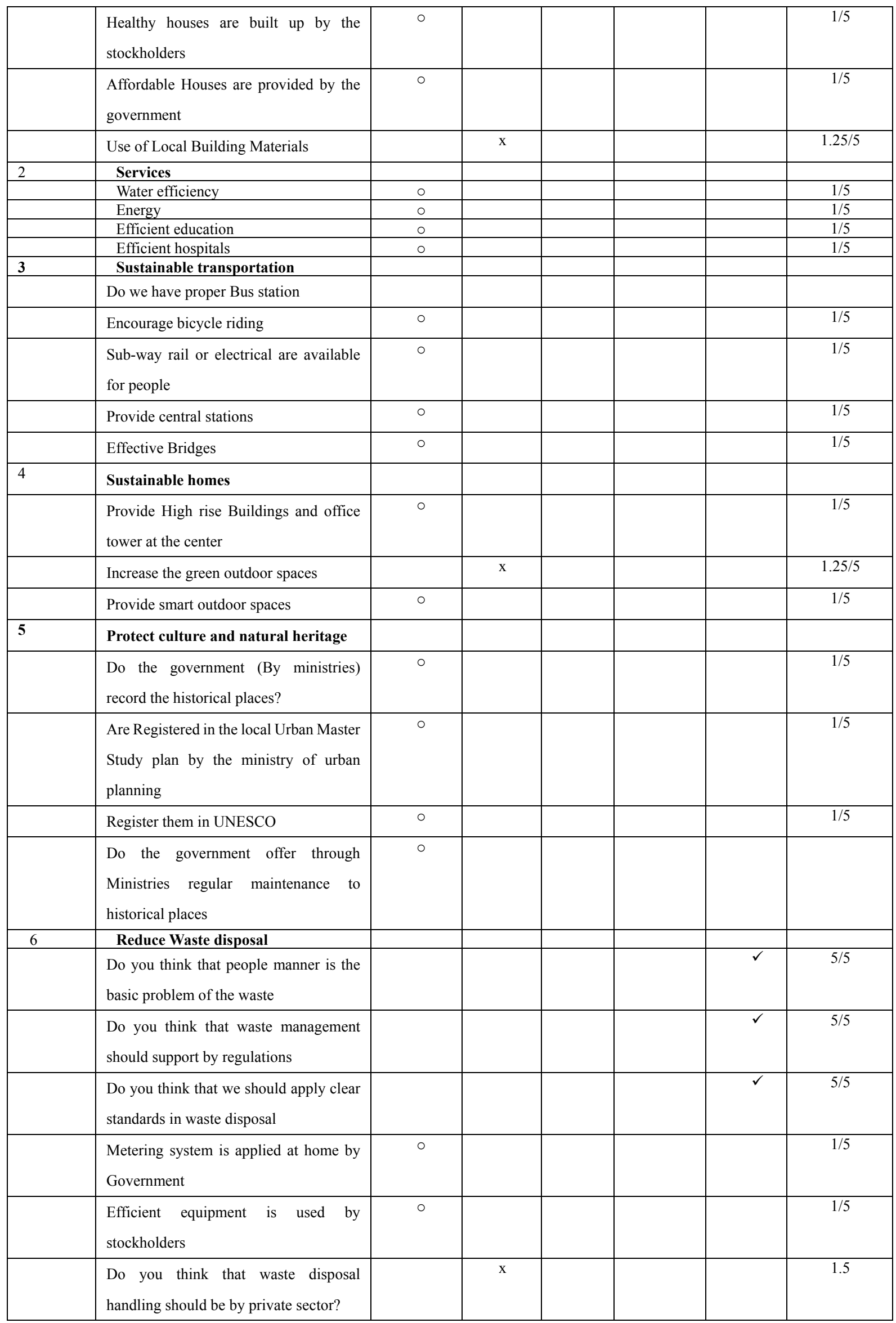




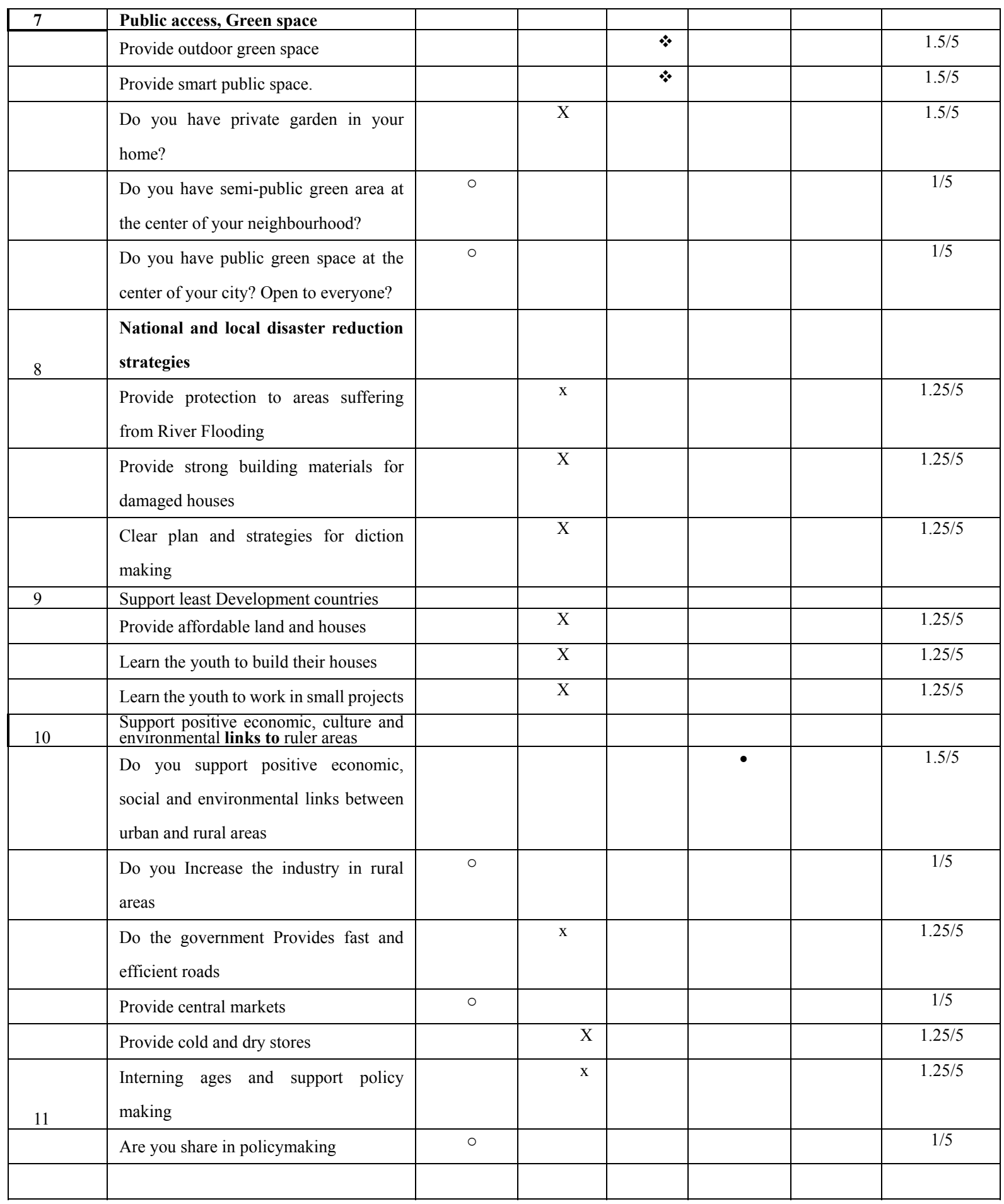

Source: Adapted by the researcher

\section{Copyrights}

Copyright for this article is retained by the author(s), with first publication rights granted to the journal.

This is an open-access article distributed under the terms and conditions of the Creative Commons Attribution license (http://creativecommons.org/licenses/by/4.0/). 